\title{
Preparation and characterization of PAN-KI complexed gel polymer electrolytes for solid-state battery applications
}

\author{
N KRISHNA JYOTHI ${ }^{1,2}$, K K VENKATARATNAM ${ }^{3}$, P NARAYANA MURTY ${ }^{2}$ and \\ K VIJAYA KUMAR ${ }^{1, *}$ \\ ${ }^{1}$ Solid State Ionics Research Laboratory, Department of Physics, K L University, Vaddeswaram 522502, India \\ ${ }^{2}$ Department of Physics, Acharya Nagarjuna University, Nagarjuna Nagar 522510, India \\ ${ }^{3}$ Department of Physics, Malaviya National Institute of Technology Jaipur, Jaipur 302017, India
}

MS received 4 July 2015; accepted 16 February 2016

\begin{abstract}
The free standing and dimensionally stable gel polymer electrolyte films of polyacrylonitrile (PAN): potassium iodide (KI) of different compositions, using ethylene carbonate as a plasticizer and dimethyl formamide as solvent, are prepared by adopting 'solution casting technique' and these films are examined for their conductivities. The structural, miscibility and the chemical rapport between PAN and KI are investigated using X-ray diffraction, Fourier transform infrared spectroscopy and differential scanning calorimetry methods. The conductivity is enhanced with the increase in $\mathrm{KI}$ concentration and temperature. The maximum conductivity at $30^{\circ} \mathrm{C}$ is found to be $2.089 \times 10^{-5} \mathrm{~S} \mathrm{~cm}^{-1}$ for PAN:KI (70:30) wt\%, which is nine orders greater than that of pure PAN $\left(<10^{-14} \mathrm{~S} \mathrm{~cm}^{-1}\right)$. The conductivity-temperature dependence of these polymer electrolyte films obeys Arrhenius behaviour with activation energy ranging from 0.358 to $0.478 \mathrm{eV}$. The conducting carriers of charge transport in these polymer electrolyte films are identified by Wagner's polarization technique and it is found that the charge transport is predominantly due to ions. The better conducting sample is used to fabricate the battery with configuration K/PAN $+\mathrm{KI} / \mathrm{I}_{2}+\mathrm{C}+$ electrolyte and good discharge characteristics of battery are observed.
\end{abstract}

Keywords. Polyacrylonitrile; solution casting technique; differential scanning calorimetry; X-ray diffraction; electrical properties.

\section{Introduction}

Recently a lot of attention has been paid to the research activities of developing gel polymer electrolytes for solid-state battery applications with good conductivity. In view of the above fact that solid-state battery has many advantages, such as higher energy density, solvent-free condition, leak proof, easy process ability and light weight [1-5]. Several earlier studies in this field are focused upon polyethylene oxide (PEO), polyvinyl alcohol, polyvinyl pyrrolidone (PVP) and polyacrylonitrile (PAN) complexed with $\mathrm{NaI}, \mathrm{NaClO}_{3}$, $\mathrm{NaYF}_{4}, \mathrm{KYF}_{4}$ and $\mathrm{LiCF}_{3} \mathrm{SO}_{3}$ [6-12]. Although very few investigations are conducted on potassium complexed polymer electrolytes, still no attention is paid on potassium salt complexed PAN-based polymer electrolytes.

Lithium batteries have advantages such as high energy density and rechargeability, which make them commercially active. Despite their advantages, they experience the ill effects of operational limitations, for example, high cost, trouble in taking care of atmospheric conditions due to high reactivity. So, the research has been focused on potassium salts due to their several advantages over lithium counterparts. Potassium is less expensive and much more abundant than lithium.

\footnotetext{
*Author for correspondence (drvijayakambila@gmail.com)
}

The smoothness of this metal makes it easier for the components of the battery to have good contact to accomplish and keep contact with other components in the battery. Moreover, potassium is more moisture resistant than lithium [13].

Compared with the other polymers, PAN-based electrolytes have been extensively studied because of their good chemical, flame resistance and electrochemical stability [14-17]. PAN is one of the most important fibre-forming polymers and is widely used because of its high strength, abrasion resistance and good insect resistance [18]. It is used to produce a large variety of products, including ultrafiltration membranes, hollow fibres for reverse osmosis, fibres for textiles, oxidized flame retardant fibres like PANOX and carbon fibre. Although the conductivity of pristine PAN is less than $10^{-14} \mathrm{~S} \mathrm{~cm}^{-1}$, this static problem confine its further applications.

PAN is usually synthesized using free radical polymerization. Generally it forms copolymers with acrylonitrile, methyl acrylate, acrylonitrile and methyl methacrylate. PAN has a glass transition point of about $107^{\circ} \mathrm{C}$ and melting point of about $319^{\circ} \mathrm{C}$, and it decomposes at this temperature [19].

To enhance the conductivity of polymer electrolytes, several techniques are suggested in the literature, including the use of blend polymers, addition of a ceramic filler, plasticizers and radiation. Two plasticizing solvents ethylene carbonate (EC) and dimethyl formamide (DMF) are chosen as solvents in this study. EC has high dielectric constant and 
low viscosity, which weakens the columbic force between cation and anion of the salt. Consequently, salt separation takes place. Further, plasticizers decrease the glass transition temperature of the polymer electrolyte and accordingly enhance the segmental motion of the polymer backbone and create free volume. Therefore, the ions can migrate easily through the void, as a result ionic conductivity increases [20]. In the present work, we have developed and study the electrical properties of PAN-based KI complexed gel polymer electrolytes and verify their potential in solid-state battery applications.

\section{Experimental}

\subsection{Materials}

Polyacrylonitrile (PAN; $\mathrm{MW}=1,50,000 \mathrm{~g} \mathrm{~mol}^{-1}$ ), ethylene carbonate (EC) were from Sigma Aldrich and potassium iodide (KI), dimethyl formamide (DMF) were from Merck. All reagents were used, as received, without further purification.

\subsection{Preparation of the gel polymer electrolyte films}

Solution casting technique was used to prepare gel polymer electrolyte films. In this method, KI was first dissolved in the mixture of EC and DMF with continuous stirring at $60^{\circ} \mathrm{C}$ for $12 \mathrm{~h}$. Then the polymer PAN was mixed with the prepared solution and the mixture was stirred up to $36 \mathrm{~h}$ to obtain a homogeneous solution. Subsequently, the prepared solution was poured into polypropylene Petri dishes and evaporated slowly at room temperature under vacuum until the gel film was formed. The polymer electrolyte samples were transferred into desiccators for further drying before the test. The films formed were mechanically stable, transparent and free standing with thickness range of $150 \mu \mathrm{m}$.

\subsection{Structural characterizations}

2.3a X-ray diffraction: To investigate the structure of the gel polymer electrolyte films, X-ray diffraction (XRD) spectra were carried out using an $X^{\prime}$ 'pert diffractometer (Philips PANalytical) with $\mathrm{CuK} \alpha$ radiation $(\lambda=1.5403 \dot{\mathrm{A}})$, and the diffraction patterns were recorded for $2 \theta$ values between $10^{\circ}$ and $90^{\circ}$.

2.3b Fourier transform infrared spectroscopy: Fourier transform infrared (FTIR) absorption spectra were recorded with the help of the Perkin Elmer FTIR spectrometer (Spectrum II USA) in the wavenumber range of $450-4000 \mathrm{~cm}^{-1}$ with spectral resolution of $2 \mathrm{~cm}^{-1}$.

2.3c Differential scanning calorimetry: The glass transition temperature $\left(T_{\mathrm{g}}\right)$ and melting temperature $\left(T_{\mathrm{m}}\right)$ of the gel polymer electrolyte films were determined using an Auto Q20
DSC, TA Instruments, at a heating rate of $10^{\circ} \mathrm{C} \mathrm{min}^{-1}$ under nitrogen atmosphere in the temperature range of $40-350^{\circ} \mathrm{C}$.

\subsection{Electrical studies}

2.4a Conductivity measurements: For conductivity measurements, circular discs of diameter $2 \mathrm{~cm}$ were cut from the films. A disc sample was sandwiched between a pair of silver electrodes and spring loaded into a sample holder of labmade conductivity setup [21]. Room temperature conductivities of films were measured using HIOKI 3532-50 LCR Hitester in $50 \mathrm{~Hz}$ to $5 \mathrm{MHz}$ frequency range.

2.4b Transport properties: Wagner's polarization method was carried out at room temperature on disc-shaped samples, which were sandwiched between silver electrodes. Polarization current was measured with respect to time in response to an applied DC bias of $1.5 \mathrm{~V}$. Ionic transport $\left(t_{\text {ion }}\right)$ and electronic transport $\left(t_{\text {ele }}\right)$ numbers were calculated using the graph of polarization current $v s$. time.

2.4c Fabrication of polymer battery: Potassium polymer battery was fabricated by sandwiching the salt complexed film as electrolyte between anode and cathode pellets with the arrangement $[\mathrm{K}$ (anode) $/(\mathrm{PAN}+\mathrm{KI}$ ) (polymer electrolyte $) /\left(\mathrm{I}_{2}+\mathrm{C}+\right.$ electrolyte) (cathode)]. This entire assembly was finally covered in the sample holder. In this battery, potassium metal was used as the anode (negative electrode). For the preparation of cathode, an accurate mixture of iodine $\left(\mathrm{I}_{2}\right)$, graphite $(\mathrm{C})$ and the electrolyte material in the wt $\%$ of $5: 5: 1$, respectively, was obtained by mechanical grinding. It was pressed in the form of pellet at a pressure of $200 \mathrm{MPa}$ after proper mixing of constituents. The battery parameters, short circuit current (SCC), open circuit voltage (OCV), current density, energy density, power density and discharge time were evaluated.

\section{Results and discussion}

\subsection{XRD analysis}

XRD measurements are performed on PAN-based KI complexed films to examine the crystallinity and the amorphous nature of the films. Figure 1 is a comparative study of the XRD patterns of pure PAN and PAN doped with different KI concentration regions. The comparative study shows that the intensity of the crystalline peak of PAN decreases gradually with the addition of KI salt (up to $30 \mathrm{wt} \%$ ) to the polymer, significant decrease in the degree of crystallinity of the electrolyte films. It may be due to the disturbance in the semicrystalline structure of the film by an addition of KI salt. The XRD pattern of the pure PAN film shows a crystalline peak at $2 \theta=17^{\circ}$, corresponding to orthorhombic PAN (110) reflection [22]. The XRD patterns show that the 


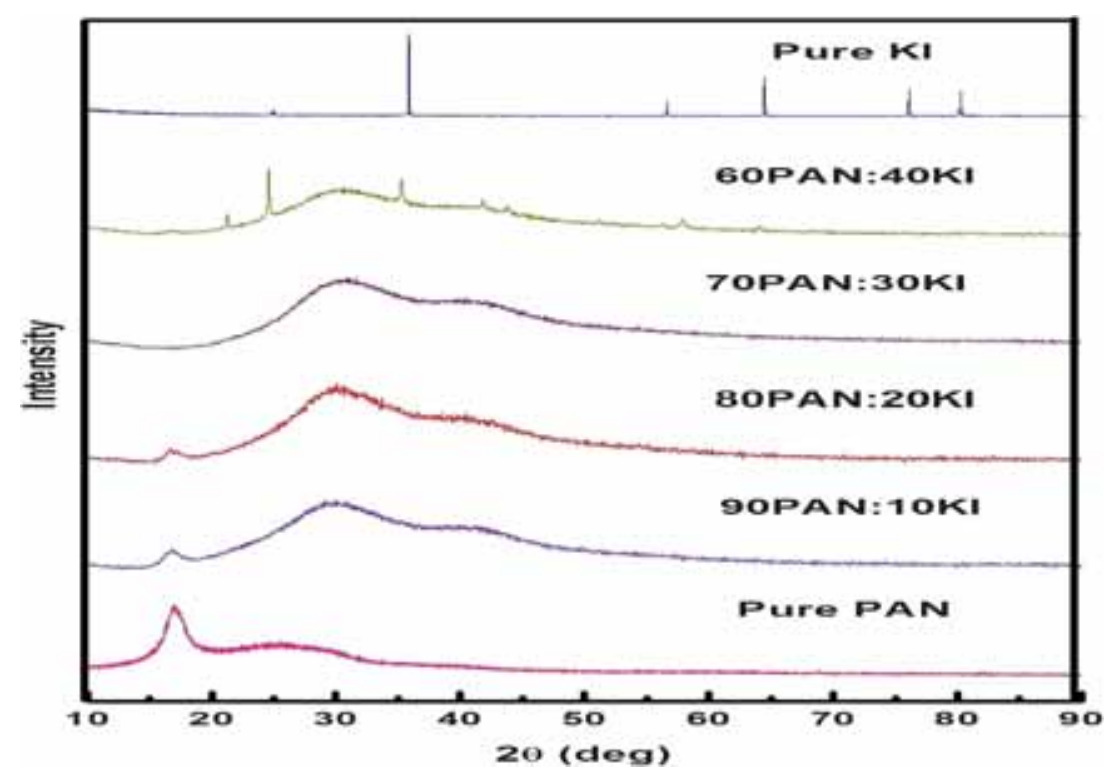

Figure 1. X-ray diffraction patterns of pure PAN, pure KI salt and PAN:KI complexed films.

semicrystalline structure is with the presence of mixed crystalline and amorphous phases. Hodge et al [23] studied a correlation between the intensity of the peak and the degree of crystallinity.

While KI salt dissolves in the PAN, the interaction between PAN and KI leads in the reduction of the intermolecular interaction among the PAN polymer chains, which decreases the crystalline phases and therefore increases the amorphous regions. The sharp crystalline peaks corresponding to KI salt are observed at $2 \theta=24.9^{\circ}, 35.8^{\circ}, 56.6^{\circ}$, $64.4^{\circ}, 76.1^{\circ}$ and $80.1^{\circ}$ (PCPDF file no. 780750 ), which are not present in the polymer electrolyte films up to $30 \mathrm{wt} \%$ salt. This indicates the complete dissolution of salt in the polymer matrix and no excess salt present in the polymer [24]. So, 70PAN:30KI gel polymer electrolyte film has more amorphous nature. The XRD pattern of 60PAN:40KI electrolyte film shows some crystalline peaks of KI. This indicates the existence of some undissolved salt in this composition, which raises the crystalline nature of the polymer electrolyte at higher concentration level of salt.

Further, in this work the percentage degree of crystallinity $(\chi)$ of pure PAN and KI complexed polymer electrolyte films are calculated from XRD patterns by using the following relation (1) [25]:

$$
\chi=\frac{S}{S_{0}} \times 100,
$$

where $S$ is the sum of the areas of all the crystalline peaks and $S_{0}$ the total area under the diffractogram. The degree of crystallinity of the pure PAN is found to be $36 \%$. For the composite films of PAN:KI, the degree of crystallinity is found to decrease to 29,24 and $19 \%$ for films of composition (90:10), (80:20) and (70:30), respectively, but for
(60:40) film the crystallinity increased to $24 \%$. From these data it is confirmed that the maximum amorphousness is in the 70:30 composite film.

\subsection{FTIR studies}

FTIR is an effective tool to analyse the local structural changes in polymers. From the vibrational frequencies, the nature of bonding and different functional groups in the polymer complex can be identified [26]. Figure 2 represents the FTIR spectra of PAN, PAN:KI films in different wt $\%$ of PAN and $\mathrm{KI}$ as well as pure $\mathrm{KI}$ in the range between 450 and $4000 \mathrm{~cm}^{-1}$. From the spectra, the absorption band observed at $2243 \mathrm{~cm}^{-1}$ can be assigned to the most characteristic band of nitrile group $\mathrm{C} \equiv \mathrm{N}$ stretching of PAN [27]. The absorption band doublet frequencies observed at 1775 and $1800 \mathrm{~cm}^{-1}$ can be assigned to $\mathrm{C}=\mathrm{O}$ stretching of $\mathrm{EC}$ and DMF. The position of these $\mathrm{C} \equiv \mathrm{N}$ and $\mathrm{C}=\mathrm{O}$ peaks are not changed with the addition of salt, but intensities have been decreased compared with that of pure PAN. It indicates that only a weak physical electrostatic interaction exists between the $\mathrm{K}^{+}$ion and $\mathrm{C}=\mathrm{O} / \mathrm{C} \equiv \mathrm{N}$.

The absorption bands at 2939, 1251, 1361 and $1455 \mathrm{~cm}^{-1}$ are assigned to $\mathrm{C}-\mathrm{H}$ stretching, $\mathrm{C}-\mathrm{H}$ wagging, $\mathrm{C}-\mathrm{H}$ partial bending and $\mathrm{C}-\mathrm{H}$ bending of pure PAN, respectively. It is observed from the spectra that there are no appreciable changes in the spectral position of these bands. The band at $865 \mathrm{~cm}^{-1}$ is assigned to $\mathrm{C}-\mathrm{H}$ rocking of pure PAN. The position of this peak has been shifted to the higher wavelength side i.e., $878 \mathrm{~cm}^{-1}$ in the mixed films. The absorption peak at $1666 \mathrm{~cm}^{-1}$ can be assigned to $\mathrm{C}=\mathrm{C}$ stretching in pure PAN. The position of this peak is shifted to $1627 \mathrm{~cm}^{-1}$ for complexed polymer electrolyte systems. The intensities of these peaks have been decreased and also broadened with the 


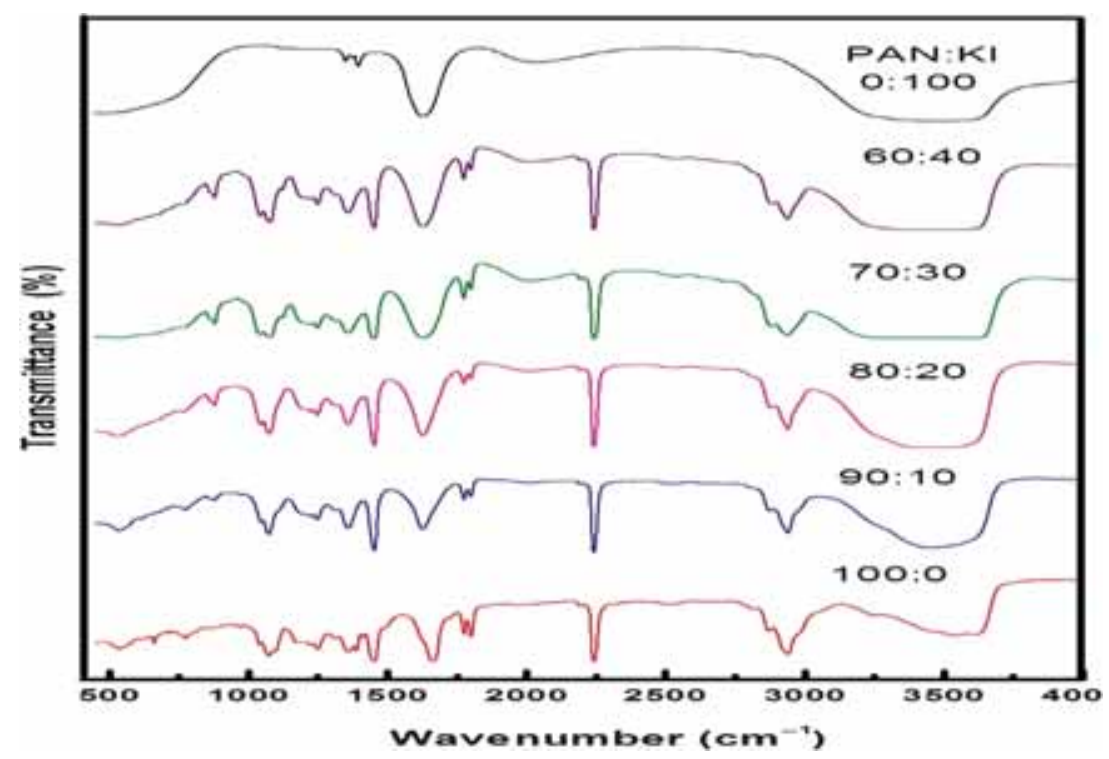

Figure 2. FTIR spectra of pure PAN, PAN complexed films for different wt $\%$ of KI and pure $\mathrm{KI}$.

addition of salt. It indicates that the complexation has occurred between PAN and KI.

\subsection{DSC studies}

Thermal properties like glass transition temperature and melting temperature of polymer electrolytes are important parameters to assure adequate performance when it is operated at high temperatures and when safety is of concern. Figure 3 shows the differential scanning calorimetric thermograms of different compositions of gel polymer electrolytes in the temperature range of $40-350^{\circ} \mathrm{C} . T_{\mathrm{g}}$ and $T_{\mathrm{m}}$ of pure PAN are 107 and $317^{\circ} \mathrm{C}$ [28]. The variations in the glass transition temperature and melting temperature are observed with variation of salt content to the pure PAN. From the differential scanning calorimetry (DSC) profile, low-intensity endothermic peak is observed around $71-90^{\circ} \mathrm{C}$ corresponding to the glass transition temperature and high-intensity exothermic peak is observed around $256-300^{\circ} \mathrm{C}$ corresponding to the melting temperature of the polymer electrolytes. It indicates that the miscibility of the polymer PAN, salt KI and plasticizers EC and DMF as the films exhibition of only single $T_{\mathrm{g}}$ and single $T_{\mathrm{m}}$ values.

From the DSC profile, the addition of plasticizing solvent DMF to the pure PAN decreases the $T_{\mathrm{g}}$ from 107 to $94^{\circ} \mathrm{C}$ and $T_{\mathrm{m}}$ from 317 to $304^{\circ} \mathrm{C}$. The inclusion of plasticizer $\mathrm{EC}$ to the PAN + DMF again decreases the $T_{\mathrm{g}}$ from 94 to $90^{\circ} \mathrm{C}$ and $T_{\mathrm{m}}$ from 304 to $300^{\circ} \mathrm{C}$. It indicates that the addition of plasticizers decreases the $T_{\mathrm{g}}$ and $T_{\mathrm{m}}$ values of polymer electrolytes due to increase in the distance between the PAN chains [29]. Besides, the $T_{\mathrm{g}}$ decreases from 90 to $71{ }^{\circ} \mathrm{C}$ gradually with salt concentrations varying from 10 to $30 \mathrm{wt} \%$, but $T_{\mathrm{g}}$ increases from 71 to $73^{\circ} \mathrm{C}$ for $40 \mathrm{wt} \% \mathrm{KI}$ concentration film, which may be due to the presence of some undissociated salt in the

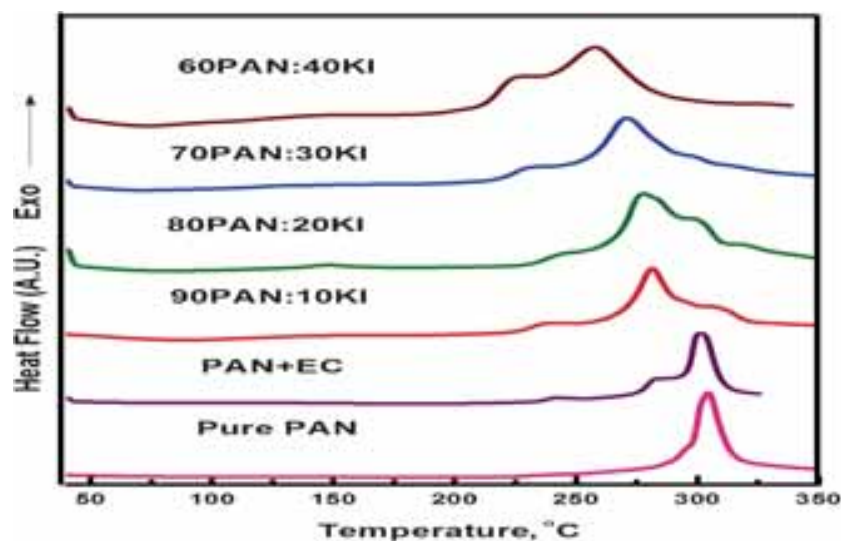

Figure 3. DSC thermograms for PAN complexed films for different wt $\%$ of $\mathrm{KI}$ from 40 to $350^{\circ} \mathrm{C}$.

polymer matrix PAN. Similarly the $T_{\mathrm{m}}$ decreases from 300 to $256^{\circ} \mathrm{C}$ gradually with salt concentrations varying from 10 to $40 \mathrm{wt} \%$ due to the interaction between PAN and KI. It is also observed that the melting temperature peaks intensity decreases and is broadened with salt concentrations from 10 to $40 \mathrm{wt} \%$. Therefore, the addition of KI decreases the $T_{\mathrm{g}}$ and $T_{\mathrm{m}}$ values [30,31]. The decrease in $T_{\mathrm{g}}$ signifies the increase in the amorphous nature of polymer electrolytes. This may be due to the plasticization effect of the electrolyte. In addition to plasticizers, salt is also found to enhance the segmental motion of the polymer electrolyte. Such segmental motion produces empty spaces, which enables the easy flow of ions in the material in the presence of electric field. The polymer electrolyte 70PAN:30KI exhibits low $T_{\mathrm{g}}$ value, indicating more amorphous nature and more flexibility compared with other polymer electrolytes, and this inference is also confirmed from XRD studies. 


\subsection{Conductivity studies}

Figure 4a shows the Cole-Cole plot for the highest conducting polymer electrolyte film 70PAN:30KI and figure $4 \mathrm{~b}$ shows the plot of its real admittance $v s$. imaginary admittance at room temperature $(303 \mathrm{~K})$. The conductivity $(\sigma)$ value of this polymer complex film is calculated from the bulk resistance $\left(R_{\mathrm{b}}\right)$ obtained from the intercept of the straight line on the real axis, area of the film $(A)$ and thickness of the film $(t)$, using the expression (2).

$$
\sigma=t / R_{\mathrm{b}} A \text {. }
$$

The conductivity values of different complexes at room temperature $(303 \mathrm{~K})$ and at $373 \mathrm{~K}$ are listed in table 1 . The intercept on the real impedance axis in the complex impedance plot is approximately the same as the reciprocal of the intercept on the real admittance axis in the complex admittance plot. The highest conductivity at ambient temperature is found to be $2.089 \times 10^{-5} \mathrm{~S} \mathrm{~cm}^{-1}$ for PAN:KI (70:30) wt $\%$. The effect of KI salt concentration on ionic conductivity of the PAN-based polymer electrolyte films at different temperatures is shown in figure 5. The conductivity of pure PAN is about $10^{-14} \mathrm{~S} \mathrm{~cm}^{-1}$ at room temperature $[32,33]$. When $30 \mathrm{wt} \%$ of $\mathrm{KI}$ is added, the ionic conductivity is observed to increase gradually up to $2.089 \times 10^{-5} \mathrm{~S} \mathrm{~cm}^{-1}$ and beyond $30 \mathrm{wt} \%$, the conductivity is decreased. With KI salt concentrations from 10 to $30 \mathrm{wt} \%$, the increase in conductivity is assigned to increase more mobile ions. Plasticizing solvent EC also helps to increase the number of charge carriers by larger dissolution of the electrolyte salt, resulting in increased conductivity. In this concentration range, the rate of ion dissociation may be greater than the rate of ion
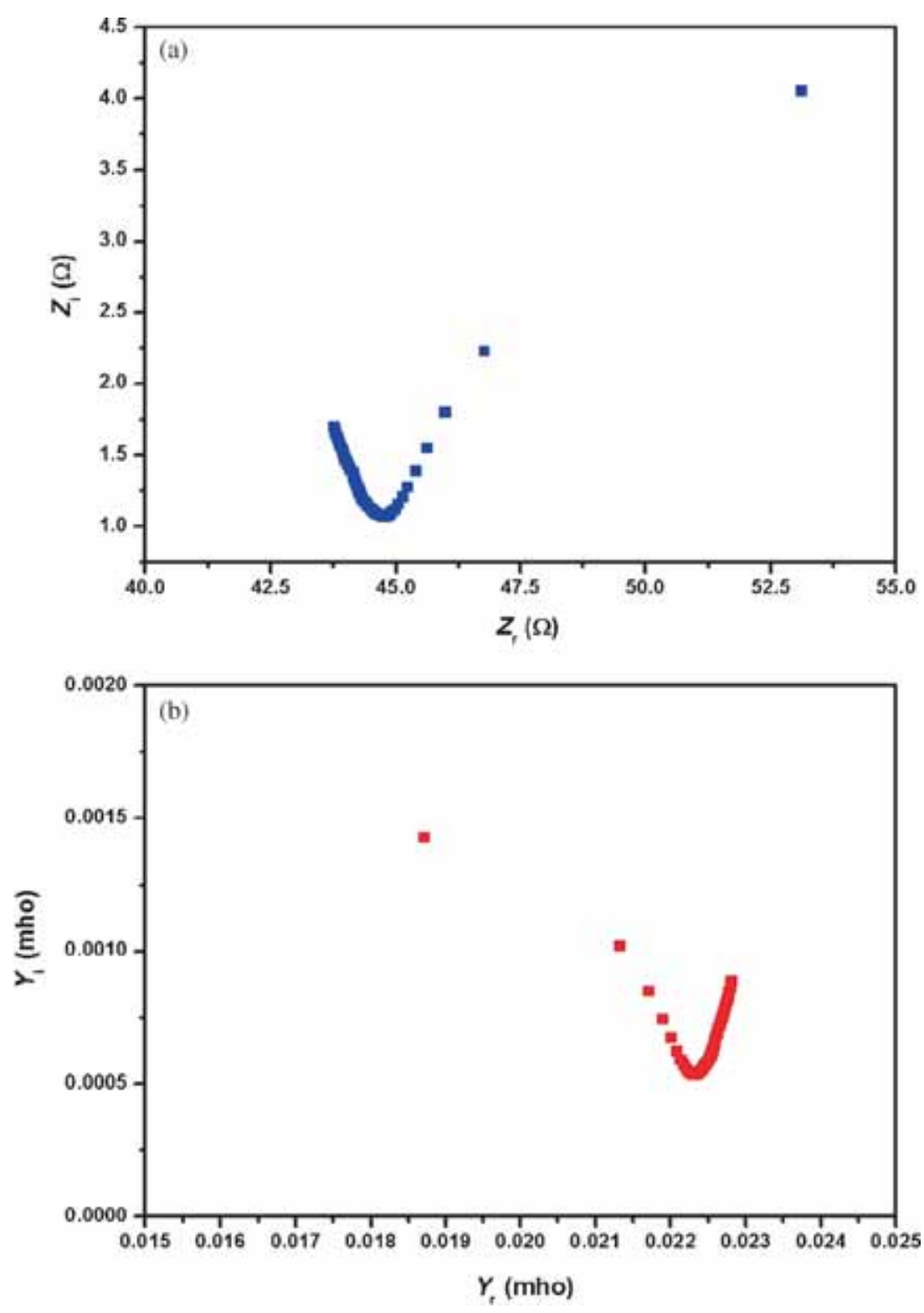

Figure 4. Complex (a) impedance and (b) admittance plots of the highest conducting film. 
Table 1. Conductivity, activation energies and transference numbers of polymer electrolyte films.

\begin{tabular}{|c|c|c|c|c|c|}
\hline \multirow[b]{2}{*}{ Polymer electrolyte } & \multicolumn{2}{|c|}{ Conductivity $\left(\mathrm{S} \mathrm{cm}^{-1}\right)$} & \multirow{2}{*}{$\begin{array}{c}\text { Activation } \\
\text { energy }(\mathrm{eV})\end{array}$} & \multicolumn{2}{|c|}{ Transference number } \\
\hline & $303 \mathrm{~K}$ & $373 \mathrm{~K}$ & & $t_{\text {ion }}$ & $t_{\mathrm{ele}}$ \\
\hline $\mathrm{PAN}+\mathrm{KI}(90: 10)$ & $1.348 \times 10^{-9}$ & $0.525 \times 10^{-7}$ & 0.47 & 0.915 & 0.084 \\
\hline $\mathrm{PAN}+\mathrm{KI}(80: 20)$ & $0.853 \times 10^{-7}$ & $0.199 \times 10^{-5}$ & 0.4 & 0.985 & 0.014 \\
\hline $\mathrm{PAN}+\mathrm{KI}(70: 30)$ & $2.089 \times 10^{-5}$ & $2.57 \times 10^{-4}$ & 0.35 & 0.99 & 0.01 \\
\hline $\mathrm{PAN}+\mathrm{KI}(60: 40)$ & $0.134 \times 10^{-5}$ & $2.04 \times 10^{-5}$ & 0.37 & 0.976 & 0.023 \\
\hline
\end{tabular}

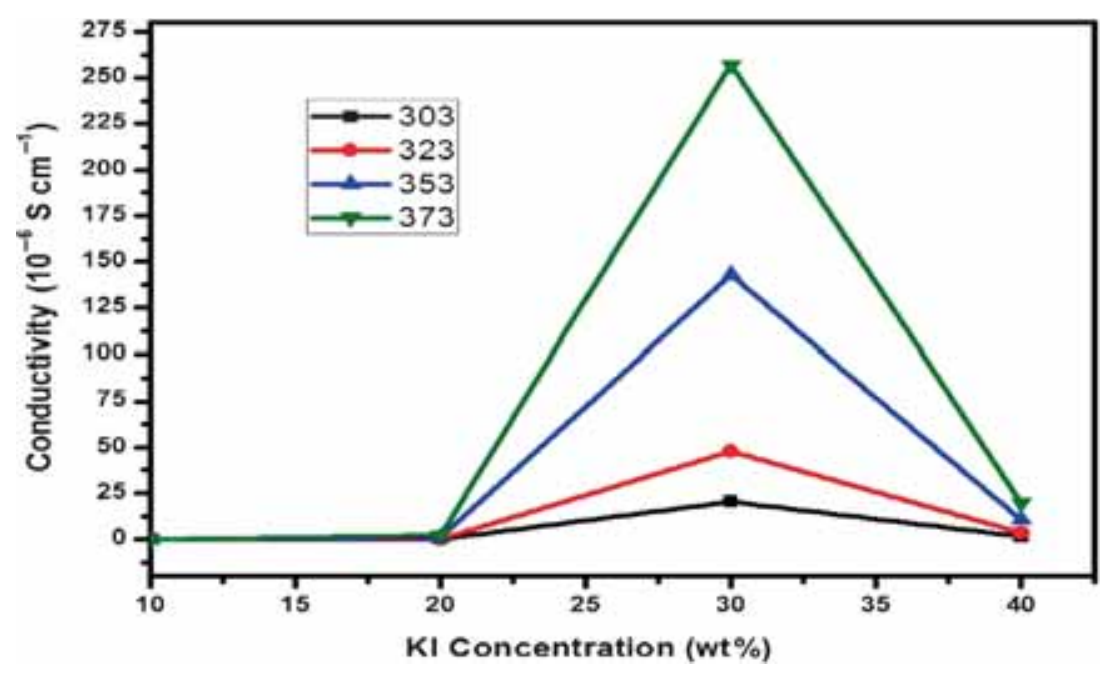

Figure 5. Ionic conductivity of polymer electrolyte films as a function of KI concentration at different temperatures.

association. While the concentration of KI salt is increased above $30 \mathrm{wt} \%$, the conductivity is decreased, which may be due to the blocking of path for moving charges by the excess of salt deposited in the paths and further, at higher concentration, there will be aggregation of ions causing ions less facile to move when potential is applied [34]. Therefore, the number of mobile ions reaching the respective electrodes is decreased and this leads to the fall in conductivity. At high salt concentrations, the mobility of the ions can decrease due to the raise in salt concentration, which will raise the viscosity of the solution [35].

The variation of logarithm of ionic conductivity with inverse of absolute temperature for various concentrations of $\mathrm{KI}$ in PAN over a temperature range of $303-373 \mathrm{~K}$ is depicted in figure 6. From the graph, it is observed that the conductivity of the polymer electrolytes increases linearly with increasing temperature for all polymer electrolytes and does not show any abrupt jump in temperature. It indicates that there is no phase transition in PAN matrix due to the addition of $\mathrm{KI}$ in the temperature range studied [36,37]. The increase in conductivity with temperature may be due to the decrease in viscosity, and hence, increase in chain flexibility [38]. This can also be explained from the view point of free volume model and hopping of charge carriers between localized sites $[39,40]$.
The polymer PAN and plasticizers EC and DMF dissociate the $\mathrm{KI}$ into $\mathrm{K}^{+}$ions and $\mathrm{I}^{-}$ions under the influence of applied electric field due to their polarity nature. The $\mathrm{K}^{+}$ions hop between the preferred nitrogen sites of PAN and oxygen sites of EC and DMF. In addition, the increasing temperature also enhances the vibrational energy of a segment which is sufficient to push against the hydrostatic pressure imposed by its neighbouring atoms and creates a small amount of space surrounding its own volume, in which vibrational motion can occur [31]. Therefore, the ions and polymer segments can move into the free volume around the polymer chain causing the mobility of ions and polymer segments, which will in turn enhance the ionic conductivity [41].

The activation energy values have been calculated, shown in figure 6, using the Arrhenius relation (3)

$$
\sigma=\sigma_{0} \exp \left(-E_{\mathrm{a}} / k T\right)
$$

where $\sigma_{0}$ is the pre-exponential factor, $E_{\mathrm{a}}$ the activation energy, $k$ the Boltzmann constant and $T$ the absolute temperature. The activation energy values of the polymer electrolytes are given in table 1 . From table 1, it is observed that as the $\mathrm{KI}$ concentration increases, the activation energy value decreases up to the composition 70PAN:30KI and again increases after that. It means that the highest conducting sample 


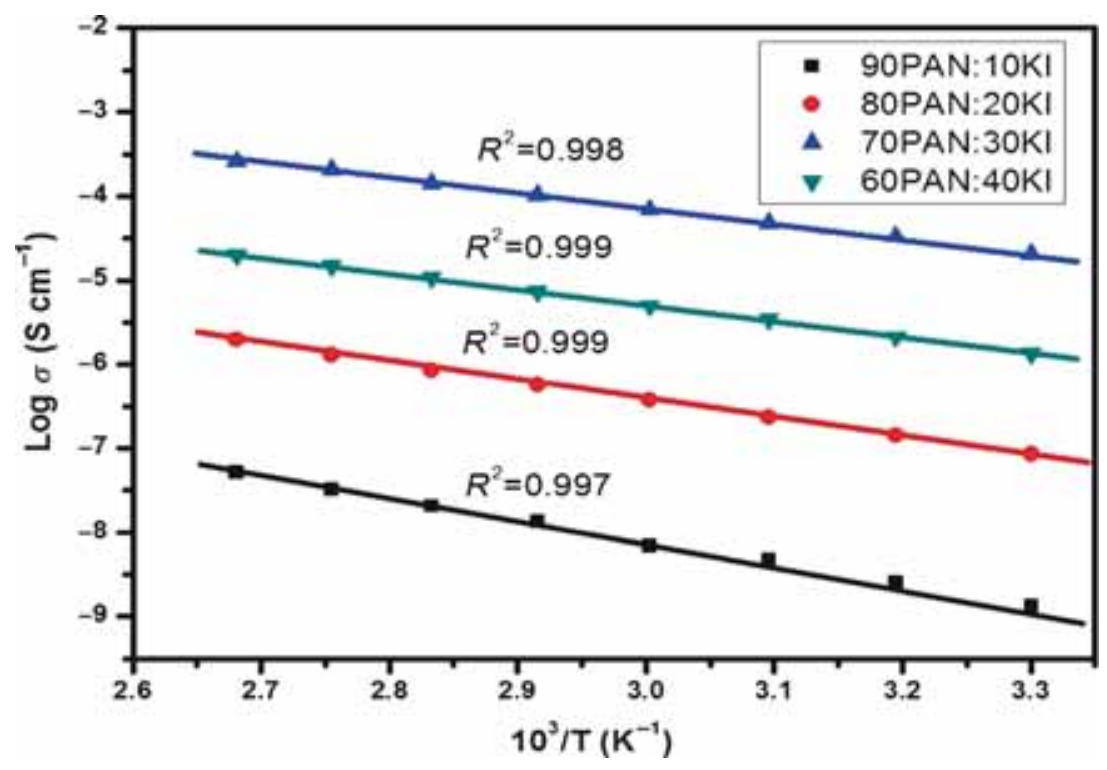

Figure 6. Plots of $\log \sigma$ vs. 1000/T for PAN complexed films for different wt $\%$ ratios of KI.

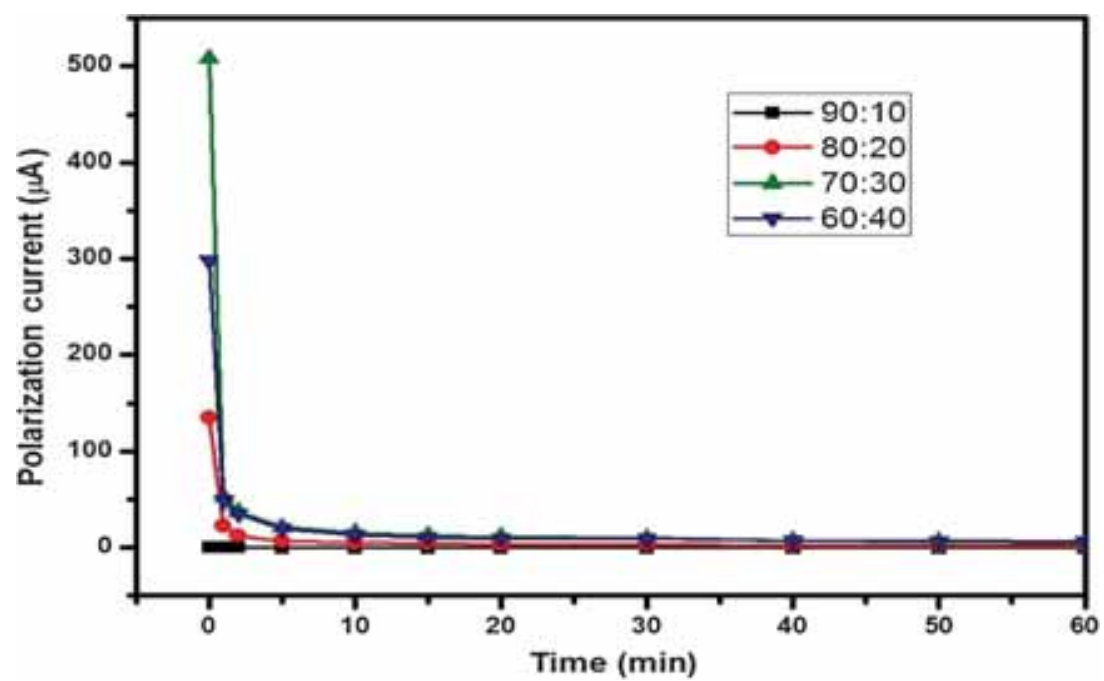

Figure 7. Transference number measurements of PAN complexed polymer electrolyte films for different wt\% ratios of KI.

gives the lowest activation energy. It may be due to the amorphous nature of the polymer electrolyte which makes easy for the ionic motion in the polymer.

\subsection{Transport properties}

For estimating the nature of types responsible for conductivity in the present electrolyte system, the transport numbers have been calculated using Wagner's polarization technique, i.e., by applying a constant $\mathrm{DC}$ potential of $1.5 \mathrm{~V}$ across the cell in the configuration $(\mathrm{Ag} / \mathrm{PAN}+\mathrm{KI} / \mathrm{Ag})$ at room temperature. The polarization current versus time plot at room temperature is shown in figure 7 . From figure, in the beginning of polarization the initial current rises up only to decay immediately and asymptotically approaches steady state after a long time of polarization, before stabilizing at a much lower level. The transference numbers $\left(t_{\text {ion }}, t_{\text {ele }}\right)$ are calculated using the equations (4) and (5),

$$
\begin{aligned}
& t_{\text {ion }}=1-I_{\mathrm{f}} / I_{\mathrm{i}}, \\
& t_{\text {ele }}=I_{\mathrm{f}} / I_{\mathrm{i}},
\end{aligned}
$$

where $I_{\mathrm{i}}$ is the initial current and $I_{\mathrm{f}}$ the final current.

The calculated transference values are given in table 1 . It is observed from the table that the ionic transport number of present polymer electrolyte systems is in the range of 0.915-0.99 and electronic transport number is in the range 


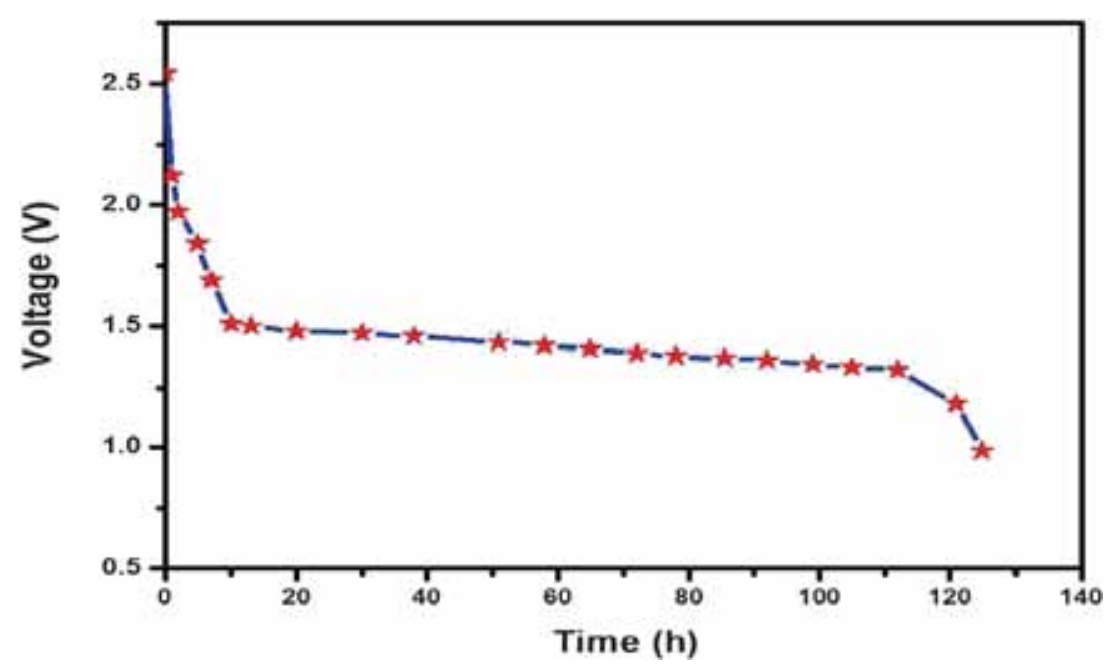

Figure 8. Discharge characteristics of 70PAN:30KI polymer electrolyte solid-state battery (at load $=100 \mathrm{k} \Omega$ ).

Table 2. Cell parameters of PAN:KI polymer electrolyte battery.

\begin{tabular}{ll}
\hline Cell parameters & $\begin{array}{l}\text { K/PAN:KI (70:30)/ } \\
\left(I_{2}+\mathrm{C}+\text { electrolyte) }\right.\end{array}$ \\
\hline Open circuit voltage & $2.54 \mathrm{~V}$ \\
Short circuit current & $1.2 \mathrm{~mA}$ \\
Effective area of the cell & $1.32 \mathrm{~cm}^{2}$ \\
Weight of the cell & $1.5 \mathrm{~g}$ \\
Discharge time for plateau region & $101 \mathrm{~h}$ \\
Current density & $0.909 \mathrm{~mA} \mathrm{~cm}^{-2}$ \\
Power density & $2.032 \mathrm{~W} \mathrm{~kg}^{-1}$ \\
Energy density & $205.2 \mathrm{~W} \mathrm{~h} \mathrm{~kg}^{-1}$ \\
Discharge capacity & $121.2 \mathrm{~mA} \mathrm{~h}^{-1}$ \\
\hline
\end{tabular}

of 0.084-0.01. It indicates that the charge transport in these polymer electrolyte systems is predominantly ionic with a negligible contribution from electrons. The ionic transport number increases with the increase of salt concentration, which is due to the enrichment of ionic concentration that results in high initial current. The ionic transport number reached a high value of 0.99 for 70PAN:30KI polymer electrolyte system, which may be sufficient to meet the requirements of solid-state electrochemical cells [42-44].

\subsection{Discharge characteristics of an electrochemical cells}

The discharge characteristics of electrochemical cells with the configuration (K/electrolyte/ $\mathrm{I}_{2}+\mathrm{C}+$ electrolyte) for highest conducting polymer electrolyte 70PAN $+30 \mathrm{KI}$ system at room temperature for constant load of $100 \mathrm{k} \Omega$ are shown in figure 8 . The half cell reactions for this configuration can be written as follows:

At the anode:

$$
K \rightarrow K^{+}+e^{-}
$$

and at the cathode:

$$
I_{2}+2 e^{-} \rightarrow 2 I^{-} \text {. }
$$

The overall reaction can be written as follows

$$
2 \mathrm{~K}+\mathrm{I}_{2} \rightarrow 2 \mathrm{KI} \text {. }
$$

As shown in figure, during discharge, the cell voltage decreases initially and then remains constant for a particular duration (time of stable performance of the cell) and after that, voltage declines. The initial sharp decrease in the voltage may be due to the activation polarization and/or to the formation of thin layer on potassium at electrode-electrolyte interface [45]. The cell parameters, such as OCV, SCC, current density, energy density, power density, plateau region (the region in which cell voltage remains constant) and discharge capacity etc., have been evaluated for the above electrochemical cell and the obtained data are listed in table 2 . From table 2, it is clear that the cell with the composition 70PAN:30KI exhibits better performance and stability than $\mathrm{PEO}+\mathrm{KYF}_{4}, \mathrm{PVP}+\mathrm{KYF}_{4}$ and $\mathrm{PEO}+\mathrm{KBrO}_{3}$ complexed polymer electrolyte systems $[13,45]$. Hence the cell developed in this research offers interesting alternatives for room temperature solid-state batteries.

\section{Conclusions}

Polyacrylonitrile-based potassium iodide complexed polymer electrolyte films are prepared by using solution casting technique. These films are characterized using XRD, FTIR and DSC techniques. The XRD and FTIR spectral studies have proved the complexation of PAN with KI. FTIR studies have confirmed that only a weak physical electrostatic interaction exists between the $\mathrm{K}^{+}$ion and $\mathrm{C}=\mathrm{O} / \mathrm{C} \equiv \mathrm{N}$. DSC studies have confirmed that the addition of plasticizers and $\mathrm{KI}$ increase the flexibility of the polymer electrolytes due to decrease in $T_{\mathrm{g}}$ and $T_{\mathrm{m}}$ values of polymer electrolytes. In the 
present study, the polymer electrolyte system 70PAN:30KI has been found to have more ionic conductivity. The ionic conductivity increases with increase of the temperature as well as in the KI concentration. The temperature dependence of ionic conductivity has exhibited an Arrhenius type thermally activated process. The charge transport in these polymer electrolyte systems is predominantly ionic with a negligible contribution from electrons. Using 70PAN:30KI gel polymer electrolyte system solid-state battery ' $\mathrm{K} / \mathrm{PAN}+$ $\mathrm{KI} / \mathrm{I}_{2}+\mathrm{C}+$ electrolyte' has been fabricated and their discharge characteristics are studied, and these results are found to be better than the existing potassium battery results.

\section{Acknowledgements}

Krishna Jyothi is very much thankful to the Department of Science and Technology (DST), Government of India, New Delhi, for awarding her with a Women Scientist's scheme under DST-WOS (A) program (File No.: SR/WOS-A/PS52/2011). We also thank Er. Koneru Satyanarayana, President, K L University, and Prof. K Ravindhranath, Department of Chemistry, for their constant support and encouragement.

\section{References}

[1] Anji Reddy P and Ranveer Kumar 2012 Intern. J. Polym. Mater. $\mathbf{6 2} 76$

[2] MacCallum J R and Vincent C A (eds) 1987 Polymer electrolyte reviews (Amsterdam: Elsevier) p 351

[3] Croce F, Appetecchi G B, Persi L and Scrosati B 1998 Nature 394456

[4] Armand M B 1983 Solid State Ionics 9-10 745

[5] Berthier C, Gorecki W, Miner M, Armand M B, Chabagno J M and Rigaud P 1983 Solid State Ionics 1191

[6] Papke B L, Ratner M A and Shriver D F 1981 J. Phys. Chem. Solids 42493

[7] Balaji Bhargav P, Sarada B A, Sharma A K and Rao V V R N 2009 J. Macromol. Sci. Part A: Pure and Appl. Chem. 47131

[8] Subba Rao C V, Ravi M, Raja V, Balaji Bhargav P, Sharma A K and Rao V V R N 2012 Iran. Polym. J. 21531

[9] Sathiyamoorthi R, Chandrasekaran R, Selladurai S and Vasudevan T 2003 Ionics 9404

[10] Chandra Sekaran R and Selladurai S 2001 J. Solid State Electrochem. 5355

[11] Sreepathi Rao S, Jaipal Reddy M, Laxmi Narsaiah E and Subba Rao U V 1995 Mater. Sci. Eng.: B 33173

[12] Yoon Hae-Kwon, Chung Won-Sub and Jo Nam-Ju 2004 Electrochim. Acta $\mathbf{5 0} 289$

[13] Sreekanth T, Jaipal Reddy M and Subba Rao U V $2001 \mathrm{~J}$. Power Sources $\mathbf{9 3} 268$

[14] Huang B, Wang Z, Li G, Huang H, Xue R, Chen L and Wang F 1996 Solid State Ionics 8579

[15] Patel M, Chandrappa K G and Bhattacharya A J 2008 Electrochim. Acta $\mathbf{5 4} 209$

[16] Sekhon S S, Arora N and Agnihotry S A 2000 Solid State Ionics 136-137 1201
[17] Subramania A, Kalyana Sundaram N T and Vijaya Kumar G 2006 J. Power Sources 153177

[18] Song J Y, Wang Y Y and Wan C C 1999 J. Power Sources 77 183

[19] Sidhu K S, Sekhon S S, Hashmi S A and Chandra S 1993 Eur. Polym. J. 29779

[20] Ahmad A, Rahman M Y A, Low S P and Hamzah H 2011 Intern. Sch. Res. Netw. 20111

[21] Vijaya Kumar K and Suneeta Sundari G 2010 J. Eng. Sci. Technol. 5130

[22] Rajendran S, Kannan R and Mahendran O 2001 Mater. Lett. 48331

[23] Hodge R M, Edward G H and Simon G P 1996 Polymer 37 1371

[24] Rajendran S and Mahendran O 2001 Ionics 7463

[25] Kumar A, Sakia D, Singh F and Avasthi D K 2005 Solid State Ionics 1761585

[26] Kuo C W, Huang C W, Chen B K, Li W B, Chen P R, Ho T H, Tseng C G and Wu T Y 2013 Intern. J. Electrochem. Sci. 83834

[27] Rajendran S, Mahalingam T and Kannan R 2000 Solid State Ionics 130143

[28] Wang C, Liu Q, Cao Q, Meng Q and Yang L 1992 Solid State Ionics 53-56 1106

[29] Dey Arup, Karan S, Dey Ashis and De S K 2011 Mater. Res. Bull. 462009

[30] Ravi M, Pavani Y, Kiran Kumar K, Bhavani S, Sharma A K and Narasimha Rao V V R 2011 Mater. Chem. Phys. 130 442

[31] Jacob M M E, Prabaharan S R S and Radhakrishna S 1997 Solid State Ionics 104267

[32] Wei Pan and Hantao Zou 2008 Bull. Mater. Sci. 31807

[33] Majid S R and Arof A K 2008 Mol. Cryst. Liq. Cryst. 484 117

[34] Chagnes A, Allouchi H, Carre B, Odou G, Willmann P and Lemordant D 2003 J. Appl. Electrochem. 33589

[35] Armand M B, Chabagno J M, Duclot M J 1979 Fast ion transport in solids $\mathrm{P}$ Vashishta, L N Mundy and G Shenoy (eds) (North Holland, Amsterdam: Elsevier) p 131

[36] Hema M, Selvasekarapandian S, Arunkumar D, Sakunthala A and Nithya H 2009 J. Non-Cryst. Solids 35584

[37] Ramesh S, Yahana A H and Arof A K 2002 Solid State Ionics 152291

[38] Miyamoto T and Shibayama K 1973 J. Appl. Phys. 44 5372

[39] Chetia J R, Maullick M, Dutla A and Dass N N 2004 Mater. Sci. Eng. B 107134

[40] Shriver D F and Ratner M A 1988 Chem. Rev. 88109

[41] Jaipal Reddy M, Sreekanth T, Chandrasekhar M and Subba Rao U V 2000 J. Mater. Sci. 352841

[42] Mohan V M, Bhargav P B, Raja V, Sharma A K and Narasimha Rao V V R 2007 Soft Mater. 533

[43] Ramya C S, Savitha T, Selvasekarapandian S and Hiran Kumar G 2005 Ionics 11436

[44] Mohan V M, Raja V, Sharma A K and Narasimha Rao V V R 2006 Ionics 12219

[45] Laxmi Narsaiah E, Jaipal Reddy M and Subba Rao U V 1995 J. Power Sources $\mathbf{5 5} 255$ 